\title{
The comparison of the wisdom view in Chinese and Western cultures
}

\author{
Zhen-Dong Wang ${ }^{1,2} \cdot$ Yi-Meng Wang $^{1,2} \cdot \mathrm{Kang} \mathrm{Li}^{3} \cdot$ Juan Shi ${ }^{1,2} \cdot$ Feng-Yan Wang $^{1,2}$ (D) \\ Accepted: 26 November 2020 / Published online: 6 January 2021 \\ (C) The Author(s), under exclusive licence to Springer Science+Business Media, LLC part of Springer Nature 2021
}

\begin{abstract}
Wisdom views in different cultural contexts are closely connected with the corresponding culture's worldview. Some results are found by comparing the wisdom concepts in Chinese and Western cultures: Firstly, the early wisdom concepts, both in China and the West, contain the elements of intelligence and virtue. Whereas, from the Enlightenment to the Piagetian school, the western concept of wisdom has then shifted to the role of cognition and knowledge; By contrast, the traditional Chinese wisdom concept has been treating wisdom as a virtue. Modern Chinese and western wisdom psychologists are inclined to accept the wisdom metatheory of "integration of intelligence and virtue". Secondly, both Chinese and the Western philosophy advocate using wisdom to solve real-life problems. Western thinkers focus on practical problems in the material world, i.e. reconciling conflicts between people and the world through understanding and changing the environment. However, Chinese philosophers focus on internal spiritual problems, i.e. improving the individual realm to solve the contradictions inside oneself. Thirdly, both China and the West highlight the comprehensive application of multiple thinking modes. While comparing with the west, which is excelled in using logical and analytical thinking modes and utilizing rational cognition, China is far better at using dialectical and holistic thinking modes and applying intuitive comprehension.
\end{abstract}

Keywords Wisdom view $\cdot$ Chinese culture $\cdot$ Western culture $\cdot$ Worldview $\cdot$ Thinking modes

\section{Introduction}

\section{Wisdom in Cultural Contexts}

As globalization deepens and new technologies flourish, humanity faces brilliant opportunities and equally formative challenges, such as economic crises, environmental pollution, resource shortages, the risks of artificial intelligence, and the most recent event, COVID-19 pandemic (Li et al., 2019). Greater wisdom that is necessary for mastering the growing complexity and uncertainty of an ever-changing world is called for (Grossmann et al., 2020).

Zhen-Dong Wang and Yi-Meng Wang contributed equally to this work.

Feng-Yan Wang

fywangjx8069@163.com

1 Institute of Moral Education, Nanjing Normal University, Nanjing 210097, China

2 School of Psychology, Nanjing Normal University, No.122, Ninghai Road, Gulou Distinct, Nanjing 210097, China

3 School of Education Science, Zhoukou Normal University, No.6, middle section of Wenchang Avenue, Chuanhui District, Zhoukou City, Henan Province 466001, China
Although the concept of wisdom has long been rooted in human history and culture, the proper study about the concept in psychology did not start until 1959 when Erickson analyzed the stages of life (Baltes and Staudinger, 1993; Yang, 2008; Chen and Wang, 2013). Erickson declared that wisdom occurs in later life, which is consistent with widespread beliefs about the relationship between wisdom and age (Erikson, 1984). However, some researches demonstrated that wisdom might present without old age. There is evidence that some adolescence and young adult are capable of displaying wisdom, which are exceptions of this rule (e.g. Pasupathi, Staudinger, and Baltes, 2001; Sternberg and Jordan, 2005; Ardelt, Pridgen, and Nutter-Pridgen, 2018). Wang and Wang (2018) divided the generally accepted correlation between wisdom and age into positive, declining, stable, and plateau four generalized views, and concluded that the relationship between wisdom and age is affected by individual differences, which primarily refer to the interaction between internal factors (heredity, maturity, and subjectivity) and external factors (cultural environment and education). Culture factors may generate the differences: for instance, compared to the individualism of Western culture, East Asians who are influenced by collectivism praise to interpersonal harmony and peaceful resolutions. Existing evidence demonstrated that young and middle-aged 
East Asians showed greater wisdom in their narratives than their American counterparts, yet the difference was not found for older participants, nor between gender (Grossmann, 2012).

Also, Ardelt (2009) found no strong differences between male and female participants who were assessed as scoring highly on a wisdom scale. But domains of reported wisdom differ between men and women (Glück, Strasser, and Bluck, 2009). When participants were asked to recall events they felt acting wisely, men tended to refer to professional instances while women to interpersonal ones. Folk beliefs about gender suggest that women are more likely to be empathetic or show consideration to others' viewpoints than men. Gender differences in social activities may offer insights to the effects that the long time social suppression through most of history have on women's contributions to public life. Further evidence is needed to unpack the role of gender for wisdom in different situational and cultural contexts (Grossmann et al., 2020).

Although, different terms of "wisdom" present in many cultures, their meanings are subject to cultural change (Grossmann and Kung, 2019; Grossmann et al., 2020). Since the rise of positive psychology and cultural psychology, an increasing number of scholars have studied the cross-cultural comparison of wisdom and obtained many discoveries. For example, Sternberg (1985), after studying the characteristic words of North American subjects, put forward the following contents: reasoning ability sagacity, learning from ideas and environment, judgment, expeditious use of information, perspicacity. Valdez (1994) explored Hispanic American wisdom through structured interviews and found that Hispanic and other Americans put more emphasis on spirituality. Levitt (1999) interviewed Tibetan Buddhist monks living in the Himalayan region, and they defined wisdom as an understanding of Buddhist notions of void and non-self. Takayama (2002) proposed four dimensions for the Japanese concept of wisdom, including knowledge and education, understanding and judgment, social and interpersonal relations, as well as introspective attitude. Takahashi and Bordia (2000) found that Americans and Australians tend to associate wisdom with being knowledgeable. In contrast, Japanese and Indians are inclined to link wisdom to a relatively direct understanding that entails some degree of emotional involvement.

These researches showed that cultures have different emphasizes on some of their wisdom views (Yang and Sternberg, 1997; Li et al., 2019). There are reasons to believe that concepts of wisdom, as an expression of culture, are formed in and by the cultural settings they are embedded (Ferrari and Alhosseini, 2019; Grossman and Kung, 2019). Human behavior, while may be wise in one cultural context, can be seen as foolish in another. Therefore, without the understanding of cultural backgrounds, wisdom cannot be fully comprehended (Sternberg, 2013).

The view of wisdom in various cultural contexts resembles the classic Indian fable "blind men guessing the elephant."
After inspecting the elephant from different angles, each of the six blind men comes up with different mental pictures of the elephant and argue about what an elephant is. Each of them only has partial comprehension of the real elephant looks. Likewise, diverse views of wisdom in different cultures may be simultaneously meaningful but not ample. Only through combining views from different cultural lenses can we promote a comprehensive, pluralistic, and stereo understanding of wisdom, which the huge elephant metaphor represents, to further facilitate the empirical researches in wisdom psychology (Grossmann et al., 2020).

In the contemporary era, facing various crises, multicultural views of wisdom should be the goal being pursued in order to mitigate conflicts and frictions among nations, polities, cultures, religions, ideological spheres, and so on, and to enhance the overall wisdom of humanity. Accepting the various cultural views of wisdom as complements can lead to a broad culturally inclusive and developmental comprehension. Therefore, it is important for researchers in wisdom psychology that begin to study actual expressions of wisdom in different cultural contexts (Staudinger and Glück, 2011).

\section{Cultures, Worldviews and Wisdom}

Cultural constructivism illustrated that culture is both the tool and the object of constant innovation of human ways of living. It can be seen as a systemic organizer of the psychological systems of individual persons, which functions within the intrapsychological systems of each person, and is co-constructed by the person relating with others, and oriented towards reaching some goals (Valsiner, 2017). The formation of human's advanced psychological function is greatly influenced by its social, cultural and historical environment. Culture and language determine the superior psychological characteristics of an individual (Vygotsky, 1978). As wisdom receives attributes from culture, it reflects the essential psychological characteristics and abilities to recognize and regulate people's relationship among themselves, others and the world. In different cultural contexts, people have their understanding of wisdom, which is closely related to different world views and epistemology formed in different cultures (Li et al., 2019).

The worldview, psychologists argue, is a kind of symbolic representation system, which integrates ourselves and everything we know about the world into a whole schema, to show us in a particular cultural environment, the reality is just like the presentation of it. Different worldviews mirror different cultural backgrounds and life experiences, moreover, provide guidance for human's thoughts and action (Lam et al., 2010). Since Plato and Aristotle, Dualism that emphasized the opposition between mind and matter, has always been the dominated principle of worldview all along in the traditional western philosophy (Labouvie-Vief, 1990). After modern philosophy sprang up in seventeenth century, the Cartesian dualistic 
worldview has deeply influenced the modern west worldview, which thinking and entities are separate and the world is divided into res extensa and res cogitans, or an objective world and a subjective world. The two separate worlds turn around in their orbits without affecting each other, only relying on God to ensure their harmony and unity (Hoffman, 1990; Li et al., 2019). In contrast, the traditional Chinese philosophy regarded the subject and the object as a "universal entity", and the boundary between the two is vague; the proposition of subject-object consistency is always carried out. This worldview leads to a deepening divergence in understanding the concept of wisdom between China and the West.

Jürgen Habermas, a German philosopher and sociologist, proposed that a sound world is a dynamic, open system, and mainly composed of three sub-worlds: the objective world, the social world, and the subjective world. (Habermas, 1984; Li et al., 2019). Whereas, Liang Shu-Ming, a representative of New Confucianism in modern China, insisted that human culture mainly deals with three sorts of problems. The first is the relationship between people and things, the solution matured in western culture; the second is the relationship between humans, the solution matured in Chinese Confucian culture; the third one is the relationship between people and being, the solution matured in Indian Buddhist culture and Chinese Taoism Culture (Liang, 1921/1999, pp.194-216). There is a corresponding relation between the two views, which indicates the wisdom generated under different cultural systems focuses on different world systems and different human relations. Figure 1 shows a comparison of the worldviews between Western and Eastern cultures under the above two views.

Consequently, along with different worldviews, wisdom in different cultures focuses on different world types and different levels of human problems since ancient times. The thoughts of wisdom by Chinese ancestors can also be traced back to thousands of years ago, and it is one of the earliest civilizations to discuss wisdom (Sternberg, 1998). Hence, in terms of wisdom, what are the similarities and differences between Chinese culture and western culture? Is the traditional wisdom view of the West and China embodied in the modern theory of wisdom psychology? There are only a handful of studies that investigated the philosophical and historical roots of wisdom in both East and West. It is crucial to further excavate the neglected soil of both Western and Chinese culture, and understand how wisdom has been viewed (Takahashi and Overton, 2002). Addressing these questions and reflecting on the traditional wisdom views, this paper compares the distinctive wisdom views of China and the West from three aspects: the relationship between intelligence and virtue, the application of wisdom, and the thinking mode of wisdom. For personality psychology and social psychology, it is vitally important to understand different types of wisdom in diverse cultural contexts and comprehend Chinese and Western wisdom views to achieve the harmonious coexistence among human beings, as well as between human and nature.

\section{The Relationship between Intelligence and Virtue in Wisdom Views}

\section{Divinity Vs Humanity}

Looking back on the origin of wisdom, ever since ancient times, the western culture has identified that wisdom is not only cognitive but also full of religion, value and morality. As early as 3000 BC, the ballads of ancient Egyptians recorded that wisdom is a cognitive tool for human beings to face difficulties and a moral and religious tool to encourage people to unite and advance (Takahashi and Bordia, 2000). Socrates (470-399 B. C.) declared that "virtue is wisdom" and Plato (428-348 B.C.) said, "Wisdom is the core of knowledge about good". Their works laid the foundation for the western concept of wisdom, that is to say, "wisdom is knowledge about universal truth and understanding of the essence of the world"'(Zhang et al., 2019). Some modern scholars even named Socrates' wisdom view - " I know nothing except the fact of my ignorance" - as "wisdom humility theory", pointing out that the limitation of human cognition is the key factor restricting the pursuit of wisdom, and no one can obtain wisdom except Gods, so the pursuit of wisdom should start from questioning the world around him/her (Wang and Zheng, 2014). Besides, Aristotle suggested that wisdom manifests in sophia and phronesis two different forms. Sophia refers to the divine ability to discern the truth; and phronesis refers to a profound social virtue: reflective, judgmental, and conversational based (Grossmann, 2012). Because of the divinity of wisdom, ancient western philosophy initially

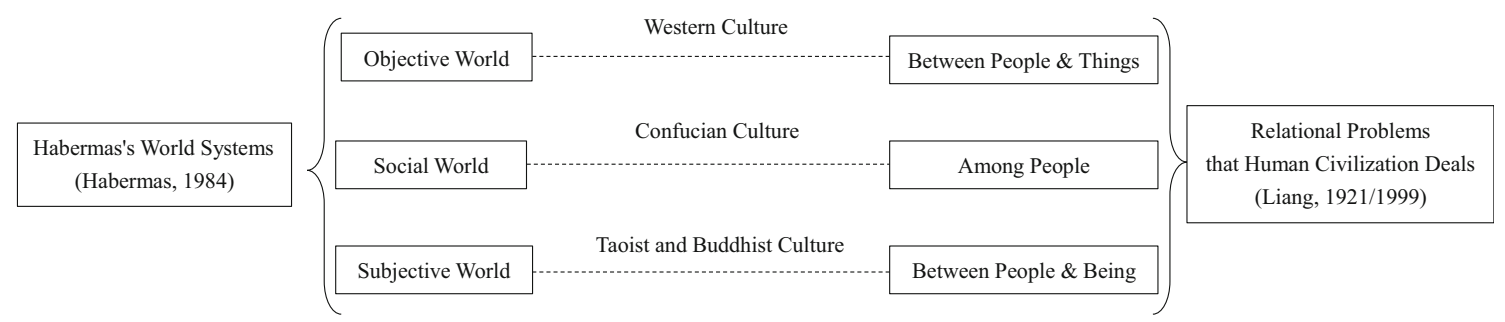

Fig. 1 Habermas' worldview and Liang Shu-Ming's view of human relations and their corresponding cultures 
regarded wisdom as a supernatural concept, intertwined with perfect virtue and self-transcendence.

However, after the Enlightenment, the view of wisdom in western culture was linked to rationality, with a heavy emphasis on human intelligence and conscious reflection. According to the concept of "holistic wisdom" put forward by Descartes, wisdom is the representative of rationality and logic, which should not contain any emotional elements. This thought was inherited by most modern philosophers, such as John Locke, Immanuel Kant, Arthur Schopenhauer, John Dewey (Sternberg and Jordan, 2005). Early psychologists who elaborated on wisdom followed Descartes' view that wisdom and intelligence are synonyms. For example, Piagetian school believed that wisdom is an integrated thinking mode in terms of post-formal cognitive operations, which requires the participation of complex cognition and comprehensive knowledge. Wise people are capable of synthesizing various knowledge and thinking from the perspective of others (Labouvie-Vief, 1990). Before post-Piagetian, the moral role of wisdom in modern Western philosophy and psychology was not sufficiently recognized, while the rational and cognitive role was over-emphasized (Grossmann et al., 2020). Therefore, for a long time, lay and academic beliefs about wisdom and intelligence concepts were mostly overlapped (Sternberg, 1985). As Takahashi and Overton (2002) summed, in the West, wisdom cannot be differentiated from knowledge for a long time at least until very recent years.

Modern psychology did not pay much attention to wisdom until the 1980s. The theories of wisdom began to regard virtue as one of the benchmarks for examining and approving the concept of wisdom. Clayton and Birren (1980) first conducted an empirical study on the folks' implicit concept of wisdom through the rating of wisdom descriptors. They found that ordinary people's wisdom view is a complex of cognition, affective and reflection, showing the coexistence and compatibility of ancient and modern descriptions of wisdom, which made scholars develop multiple views on wisdom. For example, the influential three-dimensional wisdom model proposed by Ardelt defined wisdom as a trait with cognitive, reflective, and affective dimensions: The cognitive dimension refers to the ability to understand life, that is, to comprehend the significance and deeper meaning of phenomena and events, particularly concerning intrapersonal and interpersonal matters. The reflective dimension is a prerequisite for the development of the cognitive dimension. A deeper understanding of life is only possible if one can perceive reality as it is without distortions. Items for the affective dimension should, therefore, assess the presence of positive emotions and behavior toward other beings, such as feelings and acts of sympathy and compassion, and the absence of indifferent or negative emotions and behavior toward others (Ardelt, 2003; Weststrate, Ferrari, and Ardelt, 2016). The view of the three-dimensional wisdom represents a typical implicit theory of wisdom, which is held by folk people.
Furthermore, the Berlin wisdom paradigm, which is one of the most influential explicit theory of wisdom, constructed by experts, suggested that the definition of wisdom was an expertise in the conduct and the meaning of life. Individuals following the two general, basic wisdom criteria (factual and procedural knowledge) and three meta-criteria, such as lifespan contextualism, relativism of values and life priorities, the recognition of and management of uncertainty, to deal with the problem about life. Therefore, wisdom is a key factor in the construction of a "good life", and the result of wisdom is the integration of both virtue and intelligence. He further pointed out wisdom-related knowledge are expected to offer ways and means to deal with such uncertainty about human insight and the conditions of the world, both individually and collectively, as well as humbler, more compassionate and empathic. He even regarded benign motivation as the core ingredient of wisdom (Baltes and Staudinger, 1993, 2000). Sternberg reported the balance theory of wisdom, which defined wisdom as the application of tacit as well as explicit knowledge as mediated by values toward the achievement of common good through a balance among intrapersonal, interpersonal, and extrapersonal interests, over the short and long terms, to achieve a balance among adaptation to existing environments, shaping of existing environments, and selection of new environments. Its core lies in the balance of interests and the balance of responses to the environment, which is regulated by values, and the common good includes not only the knowledge but also the motive and the result (Sternberg, 1998, 2013). Bluck and Glück (2004) pointed out that wisdom was a virtue with great value, including cognitive ability, insight, reflective attitude, concern for others and problem-solving skills. Meeks and Jeste (2009) argued that wisdom mainly consists of Pro-social attitude/behavior, practical knowledge in social decision-making/life, emotional stability, reflection/self-knowledge, value relativity/patience, understanding and effective treatment of uncertainty/ fuzziness, etc. According to Hall (2010), wisdom includes such dimensions as emotion management, moral reasoning, compassion, humility, altruism, patience, and dealing with uncertainty. Walsh (2015) also believes that wisdom, kindness and ethics are highly overlapping and interdependent virtues. Krause (2016) proved through interviews that wisdom and virtue are inseparable in the opinions of western people, which is mainly manifested in the positive correlation between wisdom and modesty, and the interaction between them affects the elderly's life satisfaction. Grossmann and Kung (2019) analysed the definitions of wisdom by 24 Western psychologists and found that 19 of them contained the sub-component of "benevolence/ prosociality".

By reviewing the history of western wisdom theory, it can be found that although ancient Greek philosophy has the tradition of cherishing both cognitive and moral factors of wisdom, since modern times, the West has been leaning to emphasize the level of cognitive component ability of 
intelligence, and, intelligence has been regarded as the synonym of wisdom (Labouvie-Vief, 1990). Early psychology focused on the study of intelligence, but, starting from three decades ago, the concept of wisdom once again drew the attention of psychologists. Nowadays, more and more western scholars emphasize the wise ability component. They also take good motivation as their core element and pay no less attention to virtue than their cognitive component (Baltes and Staudinger, 2000; Sternberg, 2013; Wang and Zheng, 2014). Recently, after synthesizing wisdom views in various cultures, Grossmann et al. (2020) proposed a "Common Wisdom Model" (CWM), which definitely contains perspectival meta-cognition and moral aspirations two principal components. The perspectival meta-cognition specifically refer to the application of certain forms of meta-cognition to reasoning and problem-solving in situational domains that have the potential to affect other people; and the moral aspirations were defined as a set of inter-related aspirational orientations toward shared humanity, pursuit of truth, balance of selfprotection and other-orientation, as well as common good orientation.

\section{Morality Vs Competence}

Compared with the West, moral aspiration attracted more attention in traditional Chinese wisdom view (Grossmann et al., 2020). In Chinese ancient literature, there are two views of wisdom can be found. The one with less impact is to understand wisdom as pure intelligence. The influential one is to interpret wisdom as a comprehensive quality closely related to morality. With an analysis of classic Chinese literature for the word zhihui (智慧or 知惠), there are writings such as “although there is wisdom, it is better to take advantage of the power; although there is foundation, it is better to wait for the time" (Mencius, Gong-Sun Chou), "Millions of defectors fled to the north and then became bad, but they were not brave enough in wisdom" (Historical Records, Volume 6). Among them, wisdom only exists as a kind of intellectual ability, which has nothing to do with morality. While "if you make the ruler of the country, you will make the unwise ruler of the country, so that the chaos of the country can be known" (Mozi, Shangxian); "people, as things, and all things have wisdom" (Lun Heng, Bian Chong) express the second understanding of wisdom (Wang and Zheng, 2014). It shows that, for many years, the two concepts of wisdom coexist, while the first concept in Confucianism is always regarded as "xiao zhi" (petty wisdom), and the later, the real wisdom, is the "da zhi" (great wisdom).

Confucianism ascribed the " $d a z h i$ " to the field of morality. Ever since Confucius, "wisdom" has been a moral principle, he compared "wisdom" with "benevolence" and "courage", and defined them as the disciplines of a junzi (noble person). Moreover, in the Analects of Confucius, he often mentioned the wise character and the moral character, which is the evidence that the intelligence and benevolence are both incorporated in early Confucianism. Mencius regarded benevolence, righteousness, propriety and wisdom as the "four virtues", and Dong Zhongshu, built upon Mencius, put forward the concept of "On the Necessity of Being Both Benevolent and Intelligent” (必仁且智, bi ren qie zhi). He listed the wisdom in "five cardinal virtues" along with benevolence, righteousness, propriety and faith, which has become the principles for later Confucians to carry out their personal cultivations. In this regard, the Emperor Taizong of the Tang Dynasty once summed it up in his article Ci Xiaoyu, "the wiser must carry both benevolence and intelligence" (Zhang et al., 2019). After Daoism became the official philosophy in Song and Ming Dynasties, wisdom was regarded as an ability to make a right and sound moral judgment, even regarded wisdom as an inseparable part of morality, which has no significance as an independent concept, which are depended on natural reason and conscience. The wiser are committed to character cultivation to embody "benevolence" and take it as the criterion, which is essentially the pursuit of moral principles (Yang, 2001).

In modern Chinese indigenous psychology, Yang (2001, 2008) conducted a series of studies to explore laypeople's wisdom concept by nominating characteristic words and summarized the concept of wisdom into four conceptual factors: Competencies and Knowledge (Basic Elements), Benevolence and Compassion (Quality to Others), Openness and Profundity (Attitude to Life), Modesty and Unobtrusiveness (Social Interaction), and proposed wisdom could be defined as a particular state. It is achieved after a person's cognition being integrated, he or she embodies ideas through action and hence brings forth positive effects to self and others. The conclusion is that the wisdom of the Chinese is highly consistent with the "benevolence" of Confucianism. Gwo (2003) pointed out that wisdom represents good judgment and foresight, and can make the so-called "wise choice", with the persistence in conscience. Zhu (2003) argued that wisdom stems from the desire to seek the truth of life, through the general knowledge, judgment and communication, prudent thinking, introspection, tolerance to accept uncertainty and exceptions, insight, the ability to find problems, and the ability to master emotions, to overcome the limitations of individuals and the environment, to pursue the well-being of humanity. Zeng (2009) believed that wisdom is an integrated, balanced and harmonious state and dynamic development process with centering on goodness, virtue and beauty, taking knowledge and emotion as the operating elements, and producing thoughtful judgments, decisions, communications and actions, and to achieve public welfare as the goal, through the interaction between individuals and external environment. Chen and Wang $(2014,2016)$ also found in their research that, in modern Chinese wisdom view, 
the words describing personal moral qualities and intelligence are used to describe the concept of wisdom, and the two have a certain distinction in semantic clustering. Furthermore, Wang and Zheng (2014) put forward the "wisdom theory of the integration of virtue and intelligence", which directly states that wisdom is a comprehensive psychological quality, which integrates both intelligence and virtue, acquired through experience and practice according to their intelligence and knowledge.

In conclusion, the implicit wisdom view of Chinese people is deeply influenced by the concept of " $d a$ zhi" (On the Necessity of Being Both Benevolent and Intelligent) in Confucianism. However, all thoughts of classical Confucianism, which acted as a "moral religion", aimed to serve morality. So wisdom was regarded as an accessory of morality, to cultivate moral personality. Contemporary Chinese people regard "virtue" and "intelligence" as two independent components of wisdom, and regard wisdom as understanding of rationality and knowledge, the insight and grasp of human nature, the meaning of life to achieve selfrealization and treat others as they would like to be treated (Yang, 2008; Tsai, 2010).

\section{The Application of Wisdom Driven by Different Culture Heritage}

\section{VENI VIDI VICI}

The ancient Greek philosophy initiated from the thought of physis, which refers to the nature of the movement of objects. Aristotle defined it as "the principle of movement and change", producing the "universe" through the process of differentiation and evolution. This principle endows the universe with a specific order. Therefore, the natural philosophy of ancient Greece emphasized on discussing the origin of the world and the whole universe (Fung, 1922). Medieval European scholasticism, influenced by both Hebrew and ancient Greek culture, sought to find well-being in heaven, according to proverbs in the Old Testament (9:10), wisdom, shown as omniscient and omnipotent to all things, begins from the love and fear of God. The wisdom of human being is limited to the daily practice of pursuing the oracle, God and absolute truth. According to this tradition, Saint Augustine divided the fields of wisdom into Scientia (wisdom of the material world) and Sapientia (knowledge of God and Christ), both aiming to pursue external transcendence (Sternberg, 1998; Yang, 2008; Wang and Zheng, 2014). Since the Middle Ages, the spirit of recognizing and proving the outside world has been continuing all along. Making imperfect human strong, intelligent and wise, one must understand, familiarize and even conquest the external world and nature (Fung, 1922). Since the seventeenth century, based on the dissemination of Cartesian worldview, people's cognition and the ability to transform the objective world have been enhanced unprecedentedly. The materialized understanding of the object world has gradually expanded from the natural world to the social world. Finally, all things become the "object" that can be developed and utilized by the subject. This world view promoted the outbreak of the scientific and technological revolution but also brought tension between human and nature. Thus, the purpose of wisdom is to understand nature, know nature and conquer nature, which has led to a series of crises such as environmental destruction, energy shortage, materialism and artificial intelligence risks ( $\mathrm{Li}$ et al., 2019).

Solving the contradiction between individuals and the world and achieving the balance between internal and external states are the fundamental perspective on the application of wisdom in modern western psychology. In Piaget's view, wisdom (intelligence) is an individual's adaptation to the external environment, a process of adjusting the internal reality to make it more in line with the external reality, and its purpose is to achieve a state of balance between the internal and external (Labouvie-Vief, 1990). The balance theory of wisdom based on the concept of tacit knowledge, which is a vital part of practical intelligence in the theory of ternary intelligence. Unlike analytical intelligence and creative intelligence, tacit knowledge is embodied in different ways of adapting, shaping and selecting diverse situations and environments. It orientates the behaviors, helps others in specific situations and emphasis on how knowledge is applied (Sternberg, 1998, 2013). The Berlin wisdom paradigm also regards wisdom as a tool for life and believes that wisdom exists for the happiness of oneself and others. The problems to be solved by wisdom include contact insight, judgment and suggestions of complex and uncertain life situations, which are closely related to real-life (Baltes and Staudinger, 1993; Baltes and Staudinger, 2000). In the three-dimensional theory of wisdom, the reflective dimension refers to the ability to perceive experience and events from multiple perspectives, including the practice of self-examination, self-awareness and self-insight. Through these practices, individuals may gradually overcome their subjectivity and projection, to perceive and accept the current reality, understand themselves and others better, and have a profound understanding of life. In this dimension, the reflected "self" exists as an object rather than a subject (Ardelt, 2003).

To sum up, the western wisdom view emphasizes people's ability to explore objects. The wisdom is used to solve the contradiction between individuals and the external world, adjust the relationship between the subject and the object through cognition, and adapt to the external environment, or make practical changes to the environment, it is also wise solution for promoting the development and progress of human understanding and utilization of nature (Liang, 1921/ 
1999; Nisbett and Miyamoto, 2005). Reviewing the history, it can also find that the western wisdom view attaches great weight to the exploration of the world, which is one of the reasons for the discovery of the new world and the first industrial revolution. In part, it reflects the tendency of westerners using wisdom to understand and change the world (Needham, 1976).

\section{Realizing Heart, Mind and Soul}

Chinese traditional culture can be summarized as a trinity pattern of Confucianism, Buddhism and Taoism. It takes Confucianism as the body and Buddhism and Taoism as the wings. With the perspective of transcendence, western traditional philosophy paid more attention to exploring nature and seeking God, while the Chinese traditional philosophy was keen on the cultivation of the inner heart, mind, and soul (Fung, 2011; Ferrari and Alhosseini, 2019).

In the Spring and Autumn period, Mencius explicitly presented the view of "Knowing your heart and knowing your nature" according to Confucius" proposition of "knowing the destiny." According to Mencius, an individual's understanding of his/her inner nature holds the key to solve the problem of life fundamentally. In the Han dynasty, Confucianism was designated as the official ideology. Dong Zhong-Shu put forward the ideas of "harmony between heaven and man", believing that the purpose of wisdom was to integrate the morality of heaven into humanity. The idea of knowing heaven with full understanding became the doctrine of accomplishment and effort of Neo-Confucianism (Fung, 2011). Following the classical Confucianism, Neo Confucianism in Song and Ming Dynasties took a further step in seeking wisdom from inside. Chu Hsi, the standard-bearer of Neo Confucianism, pointed out that "wisdom should be used to wash people's heart to get rid of evils, such as bathing their bodies to get rid of dirt", which emphasized the use of wisdom to purify people's morality, as well as to achieve the improvement of personal quality (Chu, 2016). In the Ming dynasty, the school of heart and mind represented by Wang pushed this idea to the extreme. The objective is to extend the inner conscience to everything. Neo Confucianism and Wang divided human wisdom into "knowledge of hearing and seeing" of external experience and "knowledge of virtue" of internal morality. The former, "xiao zhi", refers to the knowledge that people get through sensory contact with external things, the latter, "da zhi", is the real wisdom recognized by Confucianism. To acquire this wisdom, we should "not to be shielded from seeing and hearing", separate ourselves from the object experience. We can only rely on inner awareness, and guide by the intuitive heart (Mou, 1999).

In the pre-Qin period, Taoism school, represented by Laozi and Zhuangzi, highlighted the self-awareness and self-enlightenment, advocating that people should observe the Tao and be united with it to realize the sublimation of inner freedom and realm. However, the classic Introspect holds that "the original mind is pure, just like a mirror and water; when it is used without any hindrance, all things can be seen", which refers to the fact that the pure mind can show infinite functions only through self-sublimation and self-reshaping by adjusting the inner nature (Zhang, 1982). Therefore, the Taoist wisdom view is extremely internal, taking the improvement of people's realm as the principle of wisdom.

The concept of wisdom in Chinese Buddhism comes from the Sanskrit word Prajna, which stands for great insight into the ultimate meaning of life. Therefore, Han-Chinese Buddhism, represented by Zen School, uses selfenlightenment to obtain wisdom, which is, through self-cultivation, one sees through falsehood, demonstrates and realizes the pure Buddha-nature, and reaches Nirvana (Fung, 2011). In Buddhism, the way to get the Prajna is through vipassana (introspect) to cultivate "four mindfulness", it aims to understand the truth, detach secular troubles, and eradicate inner unwholesome roots of greed, hatred and infatuation, and get rid of the pain and get the eternal happiness (Luo, 2004).

Therefore, the Chinese traditional wisdom view has always been emphasizing the inner spiritual insight and sticking to the improvement of inner realm, including Confucianism's selfcultivation, Taoism's pursuit of inner freedom, and Buddhism's enlightenment (Fung, 2011). Moreover, how to improve the inner realm, the answer lies in "practice". The traditional Chinese culture adopts pragmatism, believing that wisdom should be "practice in daily" and "practice personally what one preaches". The wisdom acquired in daily life needs to be used in practice to test whether it is feasible. It is the inherent quality of wisdom rooted in Chinese culture (Lv and Wang, 2016). Zhang Dai-Nian, a historian of Chinese philosophy, once stated, "Chinese philosophers study the big problems of the universe and life; eventually, the theory is put into practice and verified in practice" (Zhang, 1982). Clearly, Confucianism, Buddhism and Taoism all emphasize the "integration of knowledge and practice", which deeply influence the view of implicit wisdom of modern Chinese.

The research on wisdom in contemporary Chinese psychology strongly emphasizes the importance of practices (Chen and Wang, 2016; Yang, 2008). For example, Yang (2001) found that most Taiwanese associated wisdom with achievements through practice. Hu et al. (2016) measured the implicit wisdom view in mainland China and found that wisdom consists of five components: cognitive engagement, practical engagement, social engagement, a spirituality of disengagement and a positive mindset. Therefore, the pursuit of "integration of realization and practice" has continuity from traditional to modern Chinese wisdom view.

Needham (1976), in his book Chinese History of Science and Technology, once asked: "Although ancient China made quite a lot of important contributions to the development of 
science and technology, why didn't the scientific and industrial revolution take place in modern China?" Later scholars extended the question to "why modern Chinese science is backward", "why China did not generate science". A comparative analysis of Chinese and Western wisdom shows that the wisdom view in the West focuses on "what can we have", attaching importance to the scientific method to acquire knowledge, conquer nature, and become powerful. While the Chinese often ask, "what are we?" It attaches importance to the inner world, pursuing self-realm and spiritual wellbeing through practice in daily life (Fung, 2011). Although in the early period of Chinese history (pre-Qin period), some philosophers, such as Mozi and Xunzi, encouraged the exploration, discovery and using of natural knowledge, and put forward lots of scientific ideas. However, after the establishment of the trinity of Confucianism, Taoism and Buddhism in Han and Tang dynasties, the wisdom view of Chinese went to the direction of inner pursuit and moral practice (Fung, 1922).

\section{The Thinking Mode of Wisdom in China and the West}

\section{Analytical Thinking and Propositional Logic}

Conceptualizations of wisdom often appear idiosyncratic, reflecting culture-bound attitudes toward abilities (Grossmann et al., 2020). Peng and Nisbett (1999) proved that dialectical and holistic thinking was an important manifestation of folk wisdom in Chinese culture, while western wisdom did well in applying analytical thinking characterized by a system of logic.

The western thinking mode was based on Aristotle's logocentrism, which emphasizes the law of identity, the law of non-contradiction and the principles of excluded middle. It advocates that everything is just itself. No matter how the external situation changes, $\mathrm{A}$ is $\mathrm{A}$, neither non- $\mathrm{A}$ nor $\mathrm{B}$, that is "to be is to be, not to be is not to be" (Nisbett, Peng, Choi, and Norenzayan, 2001). These three principles also embody in the western propositional logic thinking, which causes the Westerners to carry out an analytical perceptual process independent of the environment by focusing on an outstanding object, namely, analytical thinking - to separate the objects from the context, understand them only from themselves, instead of paying attention to larger facts and theories (Peng and Nisbett, 1999). This thinking mode originates from the cultural tradition of ancient Greeks, who were keen on applying wisdom to pursue truth, yearning for freedom and unwilling to be constrained. They believed that the world was not complex inherently, and people should understand the properties of objects, classify them and find their laws (Nisbett and Miyamoto, 2005; Wang, 2018). Therefore, western philosophy has given great importance to logic and reason since the beginning. Plato believed that people must understand abstract forms through rational thinking. So are the many works of ancient Greece sages who recorded their systemic logic thoughts, which takes "cognitive wisdom" and "theoretical wisdom" as essential classifications of wisdom. Descartes inherited Plato's epistemological tradition and believed that wisdom was the whole of science and the representative of rationality and logic. Compared with cognition and rationality, emotion and intuition are low-level and immature functions, which was unchanged until the rise of post-modernist philosophy (Labouvie-Vief, 1990, Takahashi and Bordia, 2000).

Much of the mid-twentieth-century empirical research on cognitive development in the Piagetian tradition has focused on propositional logic, treating it as a hallmark of sophisticated thinking (Grossmann et al., 2020). Piaget first discussed propositional logic thinking in the field of psychology. He thought that the cognitive stage in adolescence and later was "formal operation stage", which would be mature only when it developed into the "abstract logic" (Labouvie-Vief, 1990). Many theories of contemporary wisdom psychology also regarded cognitive rationality as the core feature of wisdom. For example, the first dimension in Ardelt's "ThreeDimensional Wisdom Model" is the cognitive dimension, which includes the ability to understand the deep meaning of life and both internal and external things, including knowledge, the positive and negative nature of human beings, the inherent limitation of knowledge, unpredictability of life and acceptance of uncertainty (Ardelt, 2003; Westtrate, Ferrari, and Ardelt, 2016). In the cultural psychology researches on wisdom, Takahashi (2000) also found that the concept of wisdom in the West was a psychological process and analytical model, which combines experience and knowledge, and emphasizes cognitive and analytical ability. Grossman (2017) showed great interest in the study of wise reasoning, which he believed that wisdom includes strategic humility, the ability to recognize the changes of the world and the ability to take into account other factors. In other words, wisdom represents a high level of rationality.

Overall, from the perspective of either traditional or modern western psychology, rationality and cognition have always been the core components of wisdom.

\section{Holistic Thinking and Intuitive Realization}

Some of the features of wisdom have much in common with a holistic mode of thought associated with Chinese cultural traditions. The holistic thinking favored by Chinese refers to the practice of considering the whole background, believing that everything was connected, which follows the principles of change, contradiction, relationship and integrity, and advocating that the real world is constantly changing and full of the contradictions of the unity of opposites (Nisbett et al., 2001). Nevertherless, unlike 
how the West deals with contradictions, Chinese tend to pursue the Doctrine of Mean (中庸, Zhong Yong), which is to find a balanced between conflicts and to reconcile them. It is the Chinese version of "to be or not to be" - "to be not to be, and not to be is to be" (Peng and Nisbett, 1999). These three principals embody the classic Chinese dialectical thinking mode, which makes that the wisdom view under Chinese culture capable of understanding the complex and correlated world like holism. It fully reflects the metaphor of traditional Chinese cosmology of "The universe of Yin and Yang", and believes that opposites are mutually formed. The opposites are a symbiotic concept that does not take existence as the premise, which the goal is to pursue the harmony between life and the world, rather than to discover objective knowledge or obtain the transeunt truth (Nisbett and Miyamoto, 2005; Jullien, 1998). Comparatively, the Taoist thought of "the Unity of Heaven and Human" and the benevolence thought of "extending oneself out to others" in Confucianism, all emphasize the association among people, between human and things. Also, they highlight the conformity with the current situation, and acceptance of the contradiction between the opposites. This understanding is intrinsically different from Hegelian dialectics, which pursue to solve contradictions through sublation. So it should be called Yin-Yang thinking mode (Wang, Wang, and Wang, 2019). Cross-cultural empirical researches further supported the differences in thinking mode. The studies have found that Chinese's performance was poorer than that of Americans in the Rod-and-Frame experiments. The reason was that Chinese put the target and background as a whole, so that single thing on the cognitive things cannot be separated from its environment in their cognition (Peng and Nisbett, 1999; Hou and Zhu, 2002). Currently, there were quite a lot of scientific hypotheses on the causes of this thinking mode, such as epidemic hypothesis, rice theory and water control hypothesis. These researches showed that Chinese wisdom placed a greater emphasis on the tolerance of conflict, anticipating change, and viewing problems holistically (Nisbet et al., 2001; Talkelm et al., 2014; Wang, 2018).

Additionally, some researchers suggested that western culture tended to adopt speculative and skeptical methods in solving problems, while Chinese culture did well in adopting wisdom by embracing transcendental experience and using intuitive perception. The characteristics of intuitive perception lie in the directness and wholeness of grasping objects and attach importance to the experience of "self- acquisition" (Jullien, 1998; Nisbett and Miyamoto, 2005). In traditional Chinese culture, the classics, such as I Ching, Tao Te Ching and the Art of War, all demonstrate an intuitive comprehension and realization of the universe, society and the law of life. This intuitive experience does not mean to find a balance between the Pyrrhonism and the Stoicism, but to realize the existence mode of the adaptation Tao through wisdom and fully realize of freedom of themselves (Jullien, 1998). Since the Qin and Han Dynasties, especially after the tradition of debetation of Ming School (名家, Logicians), debates have been regarded as heretical criticism. Confucianism, Buddhism and Taoism all attached great importance to the role of intuition and irrationality in the formation and application of wisdom (Mou, 1999). Chinese traditional teachings often deemphasize intellectual learning. The core of Confucius's teaching in Analects is not so much about truth finding through logic and knowledge, but about personal striving through the cultivation of one's moral and spiritual commitment to learning itself (Takahashi and Overton, 2002). In the view of Confucianism, the purpose of wisdom is to pursue "heavenly principles" or "inner conscience", which is to pursue the inherent, innate morality of inner mind, and finally realize knowledge from conscience through moral cultivation (Fung, 2011). The Confucian method of applying wisdom to solve practical problems was often without the help of logical analysis, but to realize the nature of mind by the intuitive awareness or introspect the heart. This tradition has continued to the contemporary Neo-Confucianism (Mou, 1999). Taoism relies on intuition more radically. Since Laozi and Zhuangzi, the Taoist opposes the excessive use of rationality in personal behavior and the proliferation of petty wisdom in political opinions. From Taoism's view, only comprehending, realizing and ultimately reaching the state of Tao are great wisdom (Yang, 2001). The "prajna" in Buddhism means that Buddhism breaks down illusory superstition and obtains the knowledge of the truth, which refers to the great enlightenment of the ultimate meaning of life (Luo, 2004). Chinese Buddhism further highlights the concept of "Zen". In the process of obtaining Buddhist wisdom, one should avoid persistence with words and logical thinking. The wisdom obtained is called "vid", containing personal experience including cognition, emotion, intuition and other psychological processes (Takahashi, 2000). Also, in order to gain wisdom, Buddhists selectively adopt the way of "gradual enlightenment" or "sudden enlightenment" according to the different roots of wisdom. "Zen" gives greater emphasis on sudden enlightenment in the process of generating wisdom. With the development of cognitive neuroscience, the neural mechanisms of sudden enlightenment and insight are being revealed, but the relationship between the insight and wisdom requires further study (Luo, 2004). All in all, wisdom in China is more or less a process of direct understanding, which requires a great deal of transcendent or spiritual involvement, and is without apparent intellectualization (Takahashi and Overton, 2002).

\section{Conclusion}

The comparative analysis of the traditional Chinese and Western wisdom views and that of modern psychology dwells on three aspects: the relationship between virtue and 
intelligence in the wisdom view, the field of wisdom application and the application mode of wisdom.

As to the relationship between virtue and intelligence, both Chinese and western traditional wisdom views have an emphasis on the integration of morality and intelligence. Since its origin, the West has believed that wisdom is not only cognitive but also religious, valuable and moral. Also, the mainstream Confucians in China insist that the concept of "integration of benevolence and intelligence" was the true embodiment of wisdom. Until the modern age, western philosophy embraces the cognitive and rational elements in wisdom, and often links wisdom with knowledge and intelligence, ignoring the emotional factors and morality. By comparison, Chinese philosophy emphasized the role of morality in wisdom. However, the wisdom view of contemporary Chinese tends to be following the West and insisted wisdom consists of multi-dimensional elements, and the notion of "intelligence" has separated from morality and went parallel (Ardelt, 2003; Weststrate et al., 2016; Grossmann, 2017; Chen and Wang, 2013). As to the field of wisdom application, both the East and the West are committed to applying wisdom in solving life problems, either to human's inner world or the external world. Compared with eastern culture, the West gives more emphasis on solving the problem between human and the outside world (nature) and the pursuit of natural and religious knowledge, particularly, using it to shape the world and assimilate or accommodate the environment. The traditional wisdom view of the Chinese emphasized solving the problems among people and searching the inner meaning of the soul. The solutions focus on the improvement to the inner realm of mind through moral cultivation and the practice in daily life (Liang, 1999). Additionally, there are differences between Eastern and Western thinking modes in the application of wisdom. The wisdom view in western culture prizes the role of logical thinking and knowledge, emphasizes the position of cognition and rationality. It usually separates the object from the background, uses analytical thinking mode to solve problems, and has a clear understanding of the thinking process. In contrast, the application of wisdom in Chinese culture depends on dialectical and holistic thinking. It often associates the object in the background for holistic understanding and utilizes the intuitive experience of realization and comprehension, which is characterized by a relatively vague thinking process (Takahashi and Overton, 2002).

In summary, the differences between Chinese and Western wisdom originated as early as the birth of civilization. In ancient Greece, western culture advocated to explore the external world and devoted itself to conquering the nature; while the pursuit of internal moral cultivation of Chinese culture was keen to exploring and conquering the inner world. This tradition originated from the pre-Qin period and reached its peak in the Song and Ming Dynasties. In the late Qing Dynasty, Zhang Zhi-Dong summed up Chinese and Western wisdom in the book of Encouraging Learning: "Chinese knowledge is actually the internal learning, while the Western knowledge is actually the external learning. Chinese knowledge is about mind and soul, while Western knowledge is for world and things." (Zhang, 2016). Jullien, a French sinologist, also believes that the "Logos" in Greek philosophical thoughts and the Bible have its referring (to god or truth), pursuing the truth and meaning of the objective world and the absolute knowledge and salvation. In contrast, the "Tao" in Chinese philosophy does not care about objective truth or external transcendence. Instead, it encouraged the self-cultivation to maintain internal balance and harmony but was insufficient in the emergence of modern science. All in all, Chinese philosophers are not willing to set themselves against the world, but to integrate, contain and change with the world (Jullien, 1998).

Chinese philosophy has always been pursuing "harmony without uniformity". In the current wave of globalization, communication among nations and cultures are becoming increasingly frequent. Only by seeking a balance among different wisdom views under various cultural contexts and drawing strength from the thousands of years' cultural achievements, can we deepen the understanding of humanity's overall wisdom and solve the crisis and dilemma in the modern world.

Data Availability Statement Data sharing not applicable to this article as no datasets were generated or analysed during the current study.

Funding This research was supported by National Natural Science Foundation of China (Grant No. 31971014) and the Fifth "333 Highlevel Talents Cultivation Project" of Jiangsu Province (The Influences and Mechanism of Culture on Individual Wise Performance).

\section{Compliance with Ethical Standards}

Conflict of Interests The authors declare that they have no conflicts of interest.

Ethical Approval Not applicable.

Informed Consent Not applicable.

\section{References}

Ardelt, M. (2003). Empirical assessment of a three-dimensional wisdom scale. Research on Aging, 25(3), 275-324. https://doi.org/10.1177/ 0164027503025003004

Ardelt, M. (2009). How similar are wise men and women? A comparison across two age cohorts. Research in Human Development, 6(1), 926. https://doi.org/10.1080/15427600902779354.

Ardelt, M., Pridgen, S., \& Nutter-Pridgen, K. L. (2018). The relation between age and three-dimensional wisdom: Variations by wisdom dimensions and education. Journals of Gerontology., 73(8), 13391349. https://doi.org/10.1093/geronb/gbx182.

Baltes, P. B., \& Staudinger, U. M. (1993). The search for a psychology of wisdom. Current Directions in Psychological Science, 2(3), 75-80. https://doi.org/10.1111/1467-8721.ep10770914. 
Baltes, P. B., \& Staudinger, U. M. (2000). Wisdom: A metaheuristic (pragmatic) to orchestrate mind and virtue toward excellence. American Psychologist, 55(1), 122-136. https://doi.org/10.1037/ 0003-066X.55.1.122.

Bluck, S., \& Glück, J. (2004). Making things better and learning a lesson: Experiencing wisdom across the lifespan. Journal of Personality, 72(3), 543-572. https://doi.org/10.1111/j.0022-3506.2004.00272.x.

Chen, H., \& Wang, F. (2013). Wisdom: Structure, category, measurement and relationship to related variables. Advances in Psychological Science, 27(1), 108-117. https://doi.org/10.3724/SP.J.1042.2013. 00108.

Chen, H., \& Wang, F. (2014). The experiment research on college students' implicit cognition of wisdom. Psychological Development and Education, 30(4), 363-370. https://doi.org/10.1007/s12206014-0713-2.

Chen, H., \& Wang, F. (2016). Human wisdom and natural wisdom: A classification based on wisdom-descriptive words and wisdom nominees. Psychological Exploration, 36(3), 203-210. https://doi.org/ 10.3969/j.issn.1003-5184.2016.03.003.

Chu, H. (2016). Notes to chapters and sentences of the four books. Beijing: Zhonghua Book Company.

Clayton, V., \& Birren, J. E. (1980). The development of wisdom across the lifespan: A reexamination of an ancient topic. In P. B. Baltes, D. L. Featherman, \& R. M. Lerner (Eds.), Life-span development and behavior (Vol. 3, pp. 103-135). New York: Academic Press.

Erikson, E. H. (1984). Reflections on the last stage - and the first. Psychoanalytic Study of the Child, 39, 155-165. https://doi.org/ 10.1080/00797308.1984.11823424.

Ferrari, M., \& Alhosseini, F. (2019). Cultural differences in wisdom and conceptions of wisdom. In R. Sternberg \& J. Glück (Eds.), The Cambridge handbook of wisdom (pp. 409-428). Cambridge: Cambridge University Press.

Fung, Y. L. (1922). Why China has no science - an interpretation of the history and consequences of Chinese philosophy. International Journal of Ethics, 32(3), 237-263.

Fung, Y. L. (2011). The history of Chinese philosophy. Shanghai: East China Normal University Press.

Glück, J., Strasser, I., \& Bluck, S. (2009). Gender differences in implicit theories of wisdom. Research in Human Development, 6(1), 27-44. https://doi.org/10.1080/15427600902779370.

Grossmann, I. (2012). Getting wisdom: Aging, culture, and perspective. Ann Arbor: The University of Michigan.

Grossmann, I. (2017). Wisdom in context. Perspectives on Psychological Science A Journal of the Association for Psychological Science, 12(2), 233-257. https://doi.org/10.1177/1745691616672066.

Grossmann, I., \& Kung, F. Y. H. (2019). Wisdom and culture. In S. Kitayama \& D. Cohen (Eds.), Handbook of cultural psychology (2nd ed.). New York: Guilford Press.

Grossmann, I., Weststrate, N. M., Ardelt, M., Brienza, J., Dong, M., Ferrari, M., Fournier, M., Hu, C., Nusbaum, H., \& Vervaeke, J. (2020). The science of wisdom in a polarized world: Knowns and unknowns. Psychological Inquiry, 31(2), 103-133. https://doi.org/ 10.1080/1047840X.2020.1750917.

Gwo, W. P. (2003). Adult learning: A study in psychology. Taipei: Psychology Press.

Habermas. (1984). The theory of communication action. In Reason and the Rationalization of Society (Vol. I). Boston: Beacon Press.

Hall, S. S. (2010). Wisdom: From philosophy to neuroscience. New York: Knopf.

Hoffman, P. (1990). Cartesian passions and cartesian dualism. Pacific Philosophical Quarterly, 71, 310-333. https://doi.org/10.1111/j. 1468-0114.1990.tb00406.x.

Hou, Y., \& Zhu, Y. (2002). The effect of culture on thinking style of Chinese people. Acta Psychologica Sinica, 34(1), 106-111. https:// doi.org/10.1038/sj.cr.7290131.
Hu, C., Ferrari, M., Liu, R.-D., Gao, Q., \& Weare, E. (2016). Mainland Chinese Implicit Theory of Wisdom: Generational and Cultural Differences. In Mainland Chinese implicit theory of wisdom: Generational and cultural differences (pp. 1-9). Psychological Sciences: Journals of Gerontology. https://doi.org/10.1093/geronb/ gbw157.

Jullien, F. (1998). Un sage est sans idée: Ou l'autre de la philosophie. Février: Édition Du Seuil.

Krause, N. (2016). Assessing the relationships among wisdom, humility, and life satisfaction. Journal of Adult Development, 23, 140-149. https://doi.org/10.1007/s10804-016-9230-0.

Labouvie-Vief, G. (1990). Wisdom as integrated thought: Historical and developmental perspectives. In R. J. Sternberg (Ed.), Wisdom: Its nature, origins, and development (pp. 52-83). New York: Cambridge University Press. https://doi.org/10.1017/ cbo9781139173704.005.

Lam, B. C. P., Bond, M. H., Chen, S. X., \& Wu, W. C. H. (2010). Worldviews and individual vulnerability 45 to suicide: The role of social axioms. European Journal of Personality, 24(7), 602-622. https://doi.org/10.1002/per.762.

Li, K., Wang, F., Wang, Z., Shi, J., \& Xiong, M. (2019). A polycultural theory of wisdom based on Habermas's worldview. Culture \& Psychology, 26(2), 252-273. https://doi.org/10.1177/ $1354067 X 19877915$.

Liang, S. M. (1921/1999). Eastern and western cultures and their philosophies. Beijing: The Commercial Press.

Levitt, H. M. (1999). The development of wisdom: An analysis of Tibetan Buddhist experience. The Humanistic Psychology, 39(2), 86-105. https://doi.org/10.1177/0022167899392006.

Luo, J. (2004). Neural correlates of insight. Acta Psychologica Sinica, 36(2), 219-234. https://doi.org/10.1007/BF02911031.

Lv, X. K., \& Wang, X. J. (2016). Practical wisdom: The knowledge form of Chinese indigenous psychological theories. Psychology exploration, 36(3), 199-202.

Meeks, T. W., \& Jeste, D. V. (2009). Neurobiology of wisdom: An literature overview. Archives of General Psychiatry, 66(4), 355365. https://doi.org/10.1001/archgenpsychiatry.2009.8.

Mou, Z. (1999). Mind and human nature. Shanghai: Shanghai Classics Publishing House.

Needham, J. (1976). History of science and technology in China (Vol. 15). Beijing: Science Press.

Nisbett, R. E., \& Miyamoto, Y. (2005). The influence of culture: Holistic versus analytic perception. Trends in Cognitive Sciences, 9(10), 467-473. https://doi.org/10.1016/j.tics.2005.08.004.

Nisbett, R. E., Peng, K., Choi, I., \& Norenzayan, A. (2001). Culture and systems of thought: Holistic versus analytic cognition. Psychological Review, 108(2), 291-310. https://doi.org/10.1037/ 0033-295X.108.2.291.

Pasupathi, M, Staudinger, U. M., \& Baltes, P. B. (2001). Seeds of wisdom: adolescents' knowledge and judgment about difficult life problems. Developmental Psychology, 37(3), 351-361. https://doi. org/10.1037/0012-1649.37.3.351.

Peng, K., \& Nisbett, R. E. (1999). Culture, dialectics, and reasoning about contradiction. American Psychologist, 54(9), 741-754. https://doi. org/10.1037/0003-066X.54.9.741.

Staudinger, U. M., \& Glück, J. (2011). Psychological wisdom research: Commonalities and differences in a growing field. Annual Review of Psychology, 62, 215-241. https://doi.org/10.1146/annurev.psych. 121208.131659

Sternberg, R. J. (1985). Implicit theories of intelligence, creativity, and wisdom. Journal of Personality and Social Psychology, 49(3), 607627. https://doi.org/10.1037/0022-3514.49.3.607.

Sternberg, R. J. (1998). A balance theory of wisdom. Review of General Psychology, 2(4), 347-365. https://doi.org/10.1037/1089-2680.2.4. 347. 
Sternberg, R. J., \& Jordan, J. (2005). A handbook of wisdom. New York: Cambridge University Press.

Sternberg, R. J. (2013). Personal wisdom in the balance. In M. Ferrari \& N. M. Weststrate (Eds.), The scientific study of personal wisdom (pp. 53-74). New York: Springer Netherlands.

Takahashi, M. (2000). Toward a culturally inclusive understanding of wisdom: Historical roots in the east and west. International Journal of Aging and Human Development, 51(3), 217-230. https://doi.org/10.2190/H45U-M17W-3AG5-TA49.

Takahashi, M., \& Bordia, P. (2000). The concept of wisdom: A crosscultural comparison. International Journal of Psychology, 35(1), 19. https://doi.org/10.1080/002075900399475.

Takahashi, M., \& Overton, W. F. (2002). Wisdom: A culturally inclusive developmental perspective. International Journal of Behavioral Development, 26(3), 269-277. https://doi.org/10.1080/ 01650250143000139 .

Takayama, M. (2002). The concept of wisdom and wise people in Japan. Tokyo University, Tokyo: Unpublished doctoral dissertation.

Talhelm, T., Zhang, X., Oishi, S., Shimin, C., Duan, D., Lan, X., \& Kitayama, S. (2014). Large-scale psychological differences within China explained by rice versus wheat agriculture. Science, 344(6184), 603-608. https://doi.org/10.1126/science.1246850.

Tsai, C. H. (2010). A study of wisdom of principal in elementary and junior high school. Forum of Educational Administration, 2(2), 35 54. https://doi.org/10.7038/BREE.200506.0037.

Valdez, J. M. (1994). Wisdom: A Hispanic perspective. Colorado State University, Fort Collins, CO.: Unpublished doctoral dissertation.

Valsiner, J. (2017). From cultural psychology to geropsychology: Possible contributions. GeroPsych: The Journal of Geronto psychology and Geriatric Psychiatry, 30(4), 137-143.

Vygotsky, L. (1978). Mind in society: The development of higher psychological processes. Boston, MA: Harvard University Press.

Walsh, R. (2015). What is wisdom? Cross-cultural and cross-disciplinary syntheses. Review of General Psychology, 19(3), 278-293. https:// doi.org/10.1037/gpr0000045.

Wang, F. Y. (2018). Questioning the Rice theory: Also on the internal and external causes of Chinese preference for holistic thinking. Acta Psychologica Sinica, 50(5), 572-582. https://doi.org/10.3724/SP.J. 1041.2018.00572.
Wang, F. Y., \& Wang, Y. L. (2018). Older and wiser? The relationship between wisdom and age among adults. Advances in Psychological Science, 26(1), 1-11. https://doi.org/10.3724/SP.J.1042.2018.01.

Wang, F. Y., \& Zheng, H. (2014). Theoretical exploration and applied research of wisdom psychology. Shanghai: Shanghai Educational Publishing House.

Wang, F. Y., Wang, Z. D., \& Wang, R. J. (2019). The Taiji model of self. Frontiers in Psychology, 10(1443). https://doi.org/10.3389/fpsyg. 2019.01443

Weststrate, N. M., Ferrari, M., \& Ardelt, M. (2016). The many faces of wisdom: An investigation of cultural- historical wisdom exemplars reveal practical, philosophical, and benevolent prototypes. Personality and Social Psychology Bulletin, 42(5), 662-676. https://doi.org/10.1177/0146167216638075.

Yang, S. Y., \& Sternberg, R. J. (1997). Conceptions of intelligence in ancient Chinese philosophy. Journal of Theoretical and Philosophical Psychology, 17(2), 101-119. https://doi.org/10. 1037/h0091164.

Yang, S. Y. (2001). Conceptions of wisdom among Taiwanese Chinese. Journal of Cross-Cultural Psychology, 32(6), 662-680. https://doi. org $/ 10.1177 / 0022022101032006002$

Yang, S. Y. (2008). Meanings and processes of wisdom. Indigenous Psychological in Chinese Societies, 29, 182-237. https://doi.org/ 10.6254/2008.29.185.

Zeng, J. D. (2009). A preliminary study of the leadership wisdom. Elementary Education, 49(6), 40-47.

Zhang, D. N. (1982). An outline history of Chinese philosophy. Beijing: China Social Sciences Press.

Zhang, H., Huang, J., Huang, C., Wang, W., \& Hu, C. (2019). Are wise men necessarily benevolent? A reflection upon the relationship between wisdom and virtue. Journal of Psychological Science, 42(3), 761-767. https://doi.org/10.16719/j.cnki.1671-6981.20190336.

Zhang, Z. D. (2016). China's only hope. Beijing: Zhonghua Book Company.

Zhu, Q. Y. (2003). The research orientation of wisdom and its enlightenment to the wisdom development of the elderly. Adult Education, $73,20-32$.

Publisher's Note Springer Nature remains neutral with regard to jurisdictional claims in published maps and institutional affiliations. 